\title{
Antiglycaemic potentials and molecular docking studies of the extracts of Cassia alata $\mathrm{L}$.
}

\author{
Babatunde Joseph Oso ${ }^{*}$ (D) and Ige Francis Olaoye
}

\begin{abstract}
Background: This study assessed the antiglycaemic properties of the methanolic extracts of the dried leaf of Cassia alata L. through in vitro and in silico approaches. The methanolic crude extract (MCE) of the dried leaf was prepared and partitioned into n-butanol (BPE) and aqueous (ARE) extracts. The antiglycaemic potential was assessed in vitro by studying the inhibitory actions of the extracts with a-amylase, a-glucosidase, and sucrase. The antiglycation capacity of the extracts was evaluated through the inhibition of albumin glycation, thiol oxidation, and $\beta$-fibril formation. Previously identified compounds (emodin, quercetin, chrysoeriol, and kaempferol) were docked with a-amylase (1HNY), a-glucosidase (5ZCB), and sucrase-isomaltase (3LPO) using the Pyrex Virtual Screening tool.

Results: The results revealed that MCE had the highest inhibitory potential with the lowest $I C_{50}$ values of $69.67 \pm$ $0.88,65.54 \pm 0.34$, and $48.35 \pm 1.45 \mu \mathrm{g} / \mathrm{mL}$ for a-amylase, a-glucosidase, and sucrase inhibitions, respectively. The molecular docking studies showed that quercetin and kaempferol had the best docking scores with $1 \mathrm{HNY}$ while emodin and chrysoeriol had the best scores towards 5ZCB and 3LPO. MCE and BPE significantly $(p<0.05)$ inhibited glucose-induced albumin glycation and modification.

Conclusion: This study suggested that the extract of the leaf of $C$. alata could contain a mix of different phytochemicals that could be beneficial in reducing the absorption of glucose and preventing diabetes-induced complications.
\end{abstract}

Keywords: Cassia alata L., Diabetes mellitus, Hyperglycaemia, Antiglycation, Molecular docking

\section{Background}

Diabetes mellitus is a major metabolic disease caused by an absolute or partial lack of insulin activity mostly characterized by disorders in the regulation of carbohydrate, lipid, and protein metabolisms. The disease is usually associated with high levels of blood glucose and formations of glycated compounds known as advanced glycation end products. Pathologically, diabetes mellitus has been implicated in the pathogeneses of long-term complications such as atherosclerosis, retinopathy, nephropathy, neuropathy, and microangiopathy caused by

\footnotetext{
*Correspondence: basjoe08@gmail.com; osobj@mcu.edu.ng

Department of Biochemistry, McPherson University, Seriki Sotayo, Ogun State, Nigeria
}

the elevated conversion of glucose to lipids, accumulation of sorbitol, and glycation of proteins [1,2]. Several synthetic agents used in the treatment of diabetes mellitus include acarbose (an inhibitor of carbohydratedigesting enzymes and brush border enzymes) and tolbutamide (an agonist of sulfonylurea receptor). While some of these agents achieve transiently controlled of sugar levels, they exert a number of adverse effects as induced hypoglycaemia, hepatotoxicity, cardiac duction of inte ingly accepted as the best form of treatment for tight control of blood glucose, the clinical symptoms could only be overcome particularly in young patients. Taking 
into consideration the associated contradictions of some of the synthetic drugs, research along alternative medicine is evolving for the treatment of metabolic diseases as these plants are known to contain substantial quantities of bioactive compounds that could be responsible for the anticipated health benefits. Besides, an innumerable number of the population across the world use products derived from medicinal plants for the management of several ailments that take after the symptoms of diabetes mellitus.

Thus, this study aimed at assessing the in vitro inhibitory effects of extracts of dried leaves of Cassia alata L. (Leguminosae-Caesalpiniaceae) on carbohydratemetabolizing enzymes and albumin glycation properties. This present study also analysed the binding behaviour of the bioactive components of the aerial parts of $C$. alata with amylase, glucosidase, and sucrase.

\section{Methods}

\subsection{Sample preparation}

Fresh leaves of $C$. alata were air-dried at room temperature of $29 \pm 1{ }^{\circ} \mathrm{C}$. The sample was authenticated by the Technologist in Charge of Biochemistry Laboratory, Faculty of Science, Kings University, Nigeria. The dried leaves were pulverized, and $10 \mathrm{~g}$ of each pulverized sample was extracted with $100 \mathrm{~mL}$ of methanol at room temperature of $29 \pm 1{ }^{\circ} \mathrm{C}$ for $24 \mathrm{~h}$ and later filtered. Two third of the crude extract was partitioned repeatedly inside a separating funnel into an aqueous extract and nbutanol extract. The crude extract and the partitioned extracts were used as the corresponding extracts for the subsequent analyses.

\subsection{Preparation of the crude a-glucosidase and sucrase solution}

The preparation of the crude $\alpha$-glucosidase and sucrose solution was carried out as described by Dahlqvist [6]. The animal used was handled under the approved guidelines of the Ethical Review Committee of the College of Natural and Applied Sciences, McPherson University, Seriki Sotayo, Nigeria. The mucosa of the small intestine of rats sacrificed under light anaesthesia was carefully scraped off with a glass slide, homogenized with cold sodium phosphate buffer ( $\mathrm{pH} 6.8$ ), and centrifuged at $4{ }^{\circ} \mathrm{C}$ for $20 \mathrm{~min}$ at $650 \times g$. The clear solution was used as a source of crude of $\alpha$-glucosidase and sucrase solutions.

\subsection{Inhibition of the a-amylase activity}

The determination was carried out as described by Bernfeld [7]. In a test tube containing $1.0 \mathrm{~mL}$ of $2 \mathrm{mM}$ phosphate buffer ( $\mathrm{pH} 6.9$ ), $0.1 \mathrm{~mL}$ of each extract was incubated with $0.05 \mathrm{~mL}$ of $\alpha$-amylase solution for 20 min. Precisely $0.1 \mathrm{~mL}$ of $1.0 \%$ of freshly prepared starch solution was subsequently added and allowed to stand for $5 \mathrm{~min}$. Next, $0.5 \mathrm{~mL}$ of dinitrosalicylic acid reagent held in boiling water for $5 \mathrm{~min}$. The solution was subsequently cooled, and the absorption was measured at 540 $\mathrm{nm}$. The result was expressed in $\mathrm{IC}_{50}(\mu \mathrm{g} / \mathrm{mL})$ calculated as the concentration needed for inhibition of $50 \%$ of $\alpha$ amylase activity.

\subsection{Inhibition a-glucosidase activity}

The determination was carried out as described by Kim et al. [8]. In a test tube containing $1.0 \mathrm{~mL}$ of $2 \mathrm{mM}$ phosphate buffer (pH 6.9), $0.1 \mathrm{~mL}$ of each extract was incubated with $0.1 \mathrm{~mL}$ of mucosa solution for $20 \mathrm{~min}$. Subsequently, $0.1 \mathrm{~mL}$ of $3 \mathrm{mM}$ of paranitrophenylglucopyranoside prepared in $20 \mathrm{mM}$ phosphate buffer ( $\mathrm{pH}$ 6.9) was added and allowed to stand for $15 \mathrm{~min}$. Then, $0.5 \mathrm{~mL}$ of $5.0 \%$ sodium carbonate was added and incubated for $90 \mathrm{~min}$. The absorbance at 450 $\mathrm{nm}$ was measured, and the result was expressed as the concentration of inhibition required to inhibit $50 \%$ of $\alpha$ glucosidase activity $\left(\mathrm{IC}_{50}(\mu \mathrm{g} / \mathrm{mL})\right)$.

\subsection{Assay of sucrase inhibitory activity}

The determination was carried out as described by Honda and Hara [9]. In a test tube containing $1.0 \mathrm{~mL}$ of $2 \mathrm{mM}$ phosphate buffer ( $\mathrm{pH} 6.9), 0.1 \mathrm{~mL}$ of each extract was incubated with $0.1 \mathrm{~mL}$ of mucosal solution for 20 min. Afterwards, $0.1 \mathrm{~mL}$ of $60 \mathrm{mM}$ sucrose solution was added and allowed to stand for $5 \mathrm{~min}$. Then, $0.5 \mathrm{~mL}$ of dinitrosalicylic acid reagent was transferred into the test tube and allowed to incubate in boiling water for $5 \mathrm{~min}$. The test tube was cooled, and the optical density was read at $540 \mathrm{~nm}$. The percentage inhibition of sucrase activity was calculated, and the result was expressed in $\mathrm{IC}_{50}(\mu \mathrm{g} / \mathrm{mL})$ as the inhibition concentration required to inhibit $50 \%$ of sucrase activity.

\subsection{In vitro glycation of albumin}

The preparation of glycated albumin was carried out according to the procedure defined by Safari et al. [10] with slight modifications. The solution contained bovine serum albumin $(0.1 \mathrm{~g} / \mathrm{mL})$ prepared in $0.1 \mathrm{M}$ phosphate buffer ( $\mathrm{pH}$ 7.4) containing $0.01 \%$ sodium azide and Dglucose $(10 \mathrm{mg} / \mathrm{mL})$, and the extract was combined in a ratio of 3:2:1 and incubated for $72 \mathrm{~h}$.

\subsection{Estimation of antiglycation capacity}

The determination was carried out as described by Furth [11]. In a test tube containing $1.0 \mathrm{~mL}$ of glycated sample, $0.5 \mathrm{~mL}$ of $10 \%$ trichloroacetic acid was added. For $5 \mathrm{~min}$, the solution was centrifuged at $650 \times g$. Then, $1.0 \mathrm{~mL}$ of phosphate buffer and $0.5 \mathrm{~mL}$ of $0.3 \mathrm{~N}$ oxalic acids were added to the sediment and boiled for $60 \mathrm{~min}$. The solution was cooled, and $0.5 \mathrm{~mL}$ of $10 \%$ trichloroacetic acid solution and $0.5 \mathrm{~mL} 0.05 \mathrm{M}$ thiobarbituric acid were 
added and boiled for $10 \mathrm{~min}$. The solution was centrifuged at $650 \times g$ and the absorbance of the supernatant was read at $443 \mathrm{~nm}$. The result was reported as the percentage inhibition.

\subsection{Determination of inhibition of glycation-induced oxidation of protein thiol groups}

The determination was carried out as described by

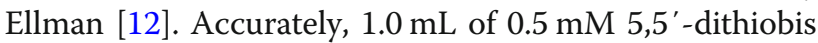
(2-nitrobenzoic acid) in $0.1 \mathrm{M}$ phosphate buffer ( $\mathrm{pH} 7.4$ ) was transferred into a test tube containing $1.0 \mathrm{~mL}$ of glycated sample and incubated at room temperature of $29^{\circ} \mathrm{C}$ for $15 \mathrm{~min}$. The absorbance at $412 \mathrm{~nm}$ was measured. The thiol group concentration was calculated using molar extinction $=1.34 \times 10^{4} \mathrm{M}^{-1} \mathrm{~cm}^{-1}$. The findings were documented as a protein of $\mathrm{nmol} / \mathrm{mg}$.

\subsection{Determination of inhibition of protein aggregation}

The determination was carried out as described by Klunk et al. [13]. Precisely, $0.1 \mathrm{~mL}$ of $1 \%$ Congo red prepared in phosphate buffer with $10 \%$ ethanol was added to a test tube containing $1.0 \mathrm{~mL}$ of glycated sample. For $30 \mathrm{~min}$, the solution was incubated and the absorption was measured at $530 \mathrm{~nm}$. The percentage of the results was reported.

\subsection{Statistical analysis}

The findings were evaluated using one-way variance analysis (ANOVA) for the mean differences between the different extracts followed by multiple comparison tests by Duncan for post hoc correlations at $p<0.05$ and reported as means \pm standard deviation of three determinations.

\subsection{Molecular docking and in silico evaluation of drug- likeness of the compounds}

The compounds selected for docking are the major compounds that are biologically active molecules as previously reported $[14,15]$. These compounds were docked with the hydrolases. The 3D SDF format structures of the compounds were obtained from the PubChem database. The compounds were emodin (PubChem CID: 3220), quercetin (PubChem CID: 5280343), chrysoeriol (PubChem CID: 5280666), and kaempferol (PubChem CID: 5280863). The target 3D structures of the enzymes were identified and retrieved from the Protein Data Bank (PDB). The enzymes were human pancreatic $\alpha$-amylase (1HNY), $\alpha$-glucosidase (5ZCB), and sucrase-isomaltase (3LPO). All the compounds and the enzymes were converted into AutoDock pdbqt format. The binding scores of the compounds and the target enzymes were measured using PyRx-Python Prescription 0.8 (The Scripps Research Institute), and the interactions were visualized using PyMOL ver. 1.1eval (De Lano Scientific LLC, CA,
USA). The computations were compared to those generated through the virtual screening of acarbose (PubChem CID: 41774) with the hydrolases. The in silico evaluation of the drug-like nature of the selected compounds was predicted using the SwissADME server (http://www.swissadme.ch/index.php) [16].

\section{Results}

The extracts exhibited varying inhibitory activities with the selected carbohydrate-digesting enzymes (Table 1). The results revealed that the extracts contained significant amounts of $\alpha$-amylase, $\alpha$-glucosidase, and sucrase inhibitors with the MCE having the highest inhibitory potential as revealed by the corresponding lowest $\mathrm{IC}_{50}$ values of $69.67 \pm 0.88,65.54 \pm 0.34$, and $48.35 \pm 1.45 \mu \mathrm{g} /$ $\mathrm{mL}$ for $\alpha$-amylase, $\alpha$-glucosidase, and sucrase inhibition respectively. This was followed by a significant inhibitory effect of BPE on the enzymes $(p<0.05)$.

The results of the virtual screening of the active phytocompounds with the selected hydrolases are presented in Table 2. The binding energies, estimated through docking studies of the compounds with the target enzymes, revealed that emodin, quercetin, chrysoeriol, and kaempferol had docking scores of $-6.0,-6.8,-5.1$, and $-6.8(\mathrm{kcal} / \mathrm{mol})$, respectively, with $\alpha$-amylase $(1 \mathrm{HNY})$. The best score towards $\alpha$-glucosidase (5ZCB) was observed for emodin $(-5.9 \mathrm{kcal} / \mathrm{mol})$ while chrysoeriol showed the highest affinity towards sucrase-isomaltase (3LPO) $(-7.7 \mathrm{kcal} / \mathrm{mol})$. The interaction between the compounds and the enzymes is depicted in Fig. 1. It was also observed that all the compounds showed intersecting molecular interactions inside the binding site of each of the enzymes (Fig. 2). The theoretical evaluation of lipophilicity ( $\log P$, calculated octanol/water partition coefficient) revealed all the selected compounds have consensus $\log P<5$ as shown in Table 3 and are druglike in nature.

The determination of antiglycation properties of the extracts was performed by investigating the inhibitory potential of the extracts against albumin glycation, oxidation of thiol groups, and $\beta$-amyloid aggregation (Table 4). There were significant differences in the inhibitory effect of the extracts against glucose-induced albumin glycation and oxidation of thiol groups. The albumin glycation inhibitory potential of BPE was statistically $(p<0.05)$ equivalent to that of MCE, but significantly higher than the value obtained from ARE. The results similarly revealed a significant decrease in the oxidation of thiol groups in the albumin-glycated sample when incubated in the presence of the extracts. It was observed that MCE and BPE exhibited significantly $(p<$ $0.05)$ higher activity than ARE. Moreover, MCE caused a significant $(p<0.05)$ and the lowest inhibition of $\beta$ amyloid aggregation $(73.43 \pm 0.57 \%)$. 
Table 1 Carbohydrate-digesting enzyme inhibitory potentials of the extracts of dried leaves of C. alata

\begin{tabular}{llll}
\hline Extracts & a-Amylase $\left(I C_{50}, \mu \mathrm{g} / \mathrm{mL}\right)$ & a-Glucosidase $\left(I C_{50}, \mu \mathrm{g} / \mathrm{mL}\right)$ & Sucrase $\left(I C_{50}, \mu \mathrm{g} / \mathrm{mL}\right)$ \\
\hline BPE & $192.04 \pm 20.31^{\mathrm{a}}$ & $143.33 \pm 0.34^{\mathrm{a}}$ & $69.67 \pm 2.96^{\mathrm{a}}$ \\
ARE & $385.66 \pm 73.39^{\mathrm{b}}$ & $338.31 \pm 1.43^{\mathrm{b}}$ & $499.33 \pm 93.27^{\mathrm{b}}$ \\
MCE & $69.67 \pm 0.88^{\mathrm{c}}$ & $65.54 \pm 0.34^{\mathrm{c}}$ & $48.35 \pm 1.45^{\mathrm{c}}$ \\
Acarbose & $24.23 \pm 2.54^{\mathrm{d}}$ & $27.17 \pm 1.22^{\mathrm{d}}$ & $31.23 \pm 3.87^{\mathrm{d}}$ \\
\hline
\end{tabular}

Different letters within the column designate significant differences $(p<0.05)$

$B P E$ butanol partitioned extract, $A R E$ aqueous residual extract, $M C E$ methanol crude extract

\section{Discussion}

The methanolic extract of $C$. alata has been reported to have strong antioxidant and anti-inflammatory properties $[17,18]$. It has also been shown to contain phenolic compounds that could be responsible for probable protection against hyperglycaemia-mediated diseases [19]. The methanolic extract was partitioned to separate the phytoconstituents into n-butanol non-polar and aqueous polar phases. A previous study had reported that kaempferol, a flavonoid, is predominant in the butanol fraction of methanolic extract of C. alata [20]. These antioxidant compounds had been suggested to be beneficial in the alleviation of complications that are associated with diabetes [21].

The results obtained revealed that the crude extract had the highest inhibitory potential towards $\alpha$-amylase, $\alpha$-glucosidase, and sucrose, hydrolases that are usually implicated in postprandial hyperglycaemia [22]. Inhibition of the activities of these enzymes could be beneficial in the control of hyperglycaemia by limiting carbohydrate digestion. However, the butanol fraction displayed higher inhibitory potential compared to the aqueous residual fraction. Although the extracts might not contain the oligosaccharides-like structure of acarbose that could aid their affinity to the glycoside hydrolases, modifications in the structural conformation of the enzymes could be induced by the phytochemical constituents of the plant. Besides, bioactive compounds from botanical sources have been reported to have hypoglycaemic effects, and these include the phenolics and the flavonoids [23, 24]. It should be noted that the activities investigated were estimated based on the weight of the dried leaves which could be higher than the activities of the respective secondary metabolites which would be accountable for the observed effects.

Further studies were carried out on the molecular mechanic assessment on the prediction of possible interactions between the bioactive components of the plant and the enzymes. The binding energies of the compound enzyme-docked complexes revealed that there could be interactions between the selected compounds and the hydrolases based on the score of the model with the least values. The enzymes, namely, human pancreatic $\alpha-$ amylase (1HNY), $\alpha$-glucosidase (5ZCB), and sucraseisomaltase (3LPO) were the selected molecular targets. These macromolecules were studied in detail to check the binding occurring between the 3D structure of the macromolecules and the compounds. Inhibition was measured by the binding energy. The binding poses obtained for the best binding compounds were visually inspected. Quercetin and kaempferol, of the four compounds selected for the study, had better interactions with $\alpha$-amylase (1HNY) based on the scoring values as indicated by the lesser binding energy. The complex with lesser binding energy had the best docking and thus the highest affinity [25]. These compounds showed similar behaviour with $\alpha$-amylase (1HNY); this could be due to the similarity in the structural conformations of these compounds in the $\alpha$-amylase (1HNY). The binding energies were compared with acarbose, a known inhibitory compound, and all the selected compounds showed higher stability than acarbose in their interactions with the $\alpha$-amylase (1HNY). Emodin had the highest comparative binding score with $\alpha$-glucosidase (5ZCB), followed by quercetin. Kaempferol showed the least stability. A good dock score was obtained from the

Table 2 Comparison of predicted binding free energies $(\mathrm{kcal} / \mathrm{mol})$ amongst the compounds

\begin{tabular}{lllll}
\hline Compounds & PubChem CID & a-Amylase (1HNY) & a-Glucosidase (5ZCB) & Sucrase-isomaltase (3LPO) \\
\hline Emodin & 3220 & -6.0 & -5.9 & -7.0 \\
Quercetin & 5280343 & -6.8 & -5.4 & -7.3 \\
Chrysoeriol & 5280666 & -5.1 & -5.2 & -7.7 \\
Kaempferol & 5280863 & -6.8 & 3.4 & -7.1 \\
Acarbose & 41774 & 7.5 & -3.2 & -7.0 \\
\hline
\end{tabular}



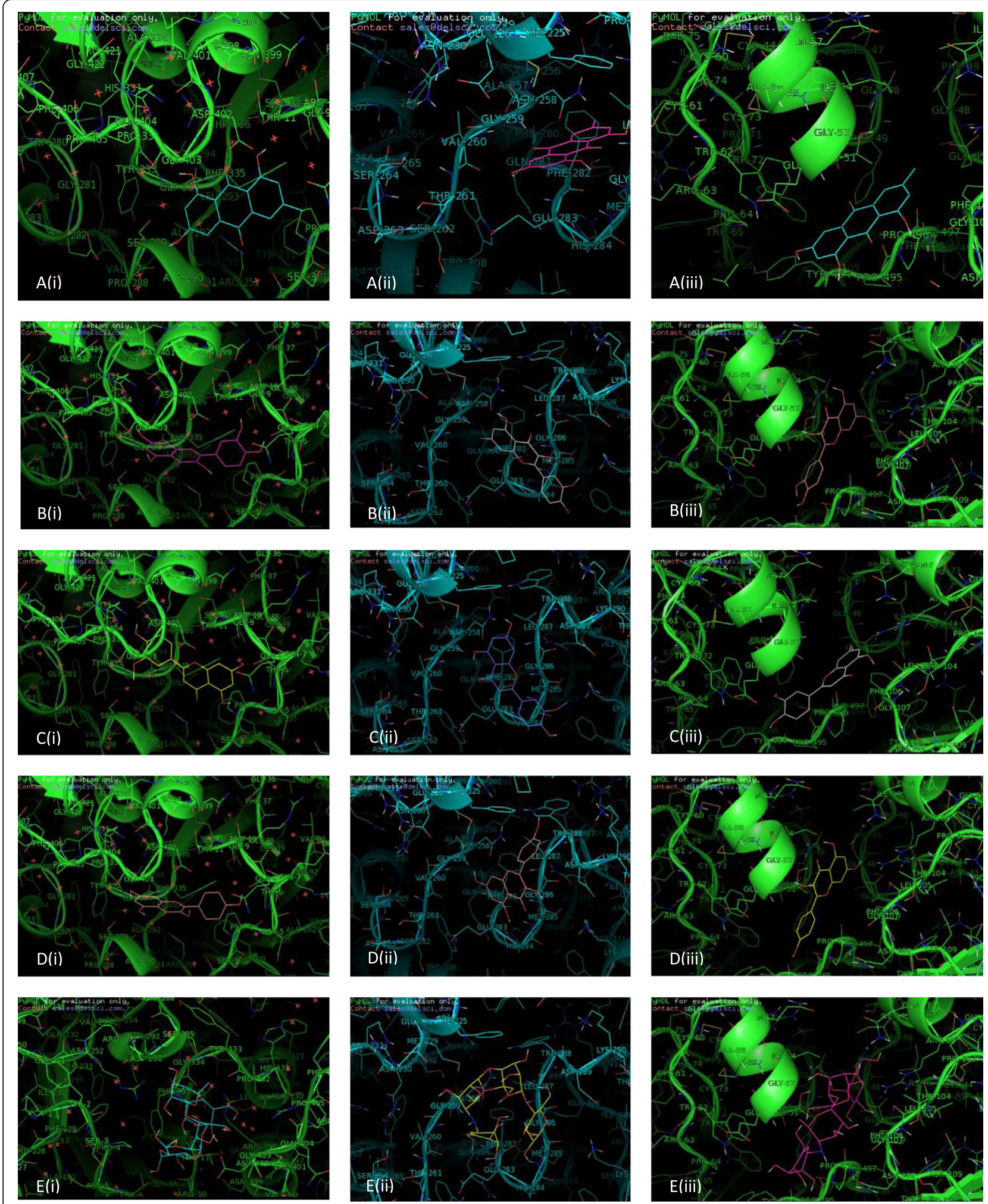

Fig. 1 Molecular docking of the compounds with the enzymes $\mathbf{A}$ (i) emodin and a-amylase (1HNY), $\mathbf{A}$ (ii) emodin and a-glucosidase (5ZCB), $\mathbf{A}$ (iii) emodin and sucrase-isomaltase (3LPO), B(i) quercetin and amylase, B(ii) quercetin and a-glucosidase (5ZCB), B(iii) quercetin and sucrase-

isomaltase (3LPO), C(i) chrysoeriol and amylase (1HNY), C(ii) chrysoeriol and a-glucosidase (5ZCB), C(iii) chrysoeriol and sucrase-isomaltase (3LPO), D(i) kaempferol and amylase (1 HNY), D(ii) kaempferol and a-glucosidase (5ZCB), D(iii) kaempferol and sucrase-isomaltase (3LPO), E(i) acarbose and amylase (1HNY), E(ii) acarbose and a-glucosidase (5ZCB), and E(iii) acarbose and sucrase-isomaltase (3LPO) 

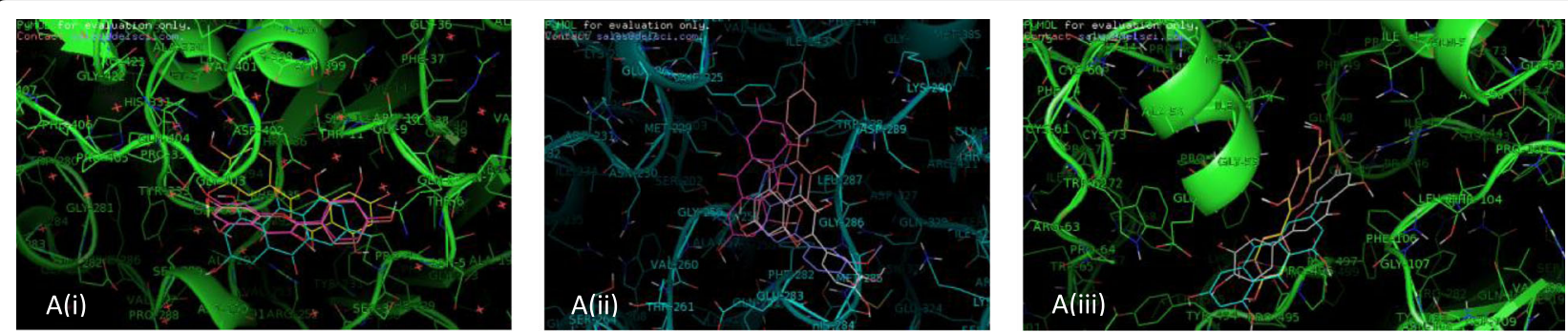

Fig. 2 Superimposition of 3D structures of emodin, quercetin, chrysoeriol, and kaempferol inside the binding site of $\mathbf{A}(\mathbf{i})$ a-amylase (1HNY), $\mathbf{A}(\mathbf{i i})$ a-glucosidase (5ZCB), and $\mathbf{A}$ (iii) sucrase-isomaltase (3LPO)

interactions of all the compounds and acarbose with sucrase-isomaltase (3LPO), showing the compounds inhibit the enzyme effectively. However, by comparing the computed binding affinities, it was observed that chrysoeriol exhibited the highest binding energy with sucrase-isomaltase (3LPO). This could substantiate the reported hyperglycaemia-ameliorative effects of chrysoeriol in diabetic rats [26].

The docking studies of the compounds with the target enzymes related to hyperglycaemia showed that the methanolic extract of the leaf of $C$. alata could contain good inhibitors that could interfere with the target hydrolases compared to acarbose and limit the rate of glucose absorption in the gut.

There are thousands of active compounds in plantbased foods; the roles they play in reducing the risk of chronic diseases and maintenance of wellness could result from the integration and synergistic action of these secondary metabolites. Thus, interactions between these compounds could result in synergistic effects and increase the observed pharmacological activity, and probably the shrub's therapeutic effects as depicted through the superimposition of the docked compounds inside the binding sites of the enzymes.

The drug-likeness of the selected compounds evaluated by the molecular weight and logarithm of the partition coefficient $(\log P)$ showed that all the compounds are drug-like molecules with values within the acceptance range $(\log P \leq 5.0$, molecular weight $\leq 500 \mathrm{~g} / \mathrm{mol}$ ) [27]. Moreover, the evaluation through the Ghose rules also showed each of the compounds has a molecular weight that is less than 480 and lipophilicity $(\log P)$ within the range of -0.4 and 5.6 (Table 3) [28].
Additionally, many of the secondary complications that are associated with diabetics are stemmed from the elevation in blood glucose concentrations. Typically, the antioxidant potential of plant extracts has been considered being positively associated with inhibition of diabetesinduced complications [29]. Glycation is a non-enzymatic reaction between reducing sugars and free amino groups in biomolecules. It generates unstable Schiff base structures and Amadori products that could go through a series of transformations and form advanced glycation end products (AGEs) [30]. The investigation of the attenuation of glycation-induced protein modifications revealed that MCE could cause a significant reduction in the glycation of albumin at the selected concentration. Moreover, oxidative stress has been shown to be worsened in chronic diabetic condition. Generation of AGEs could be associated with the generation of intracellular reactive oxygen species and the release of pro-inflammatory molecules [31]. Hence, prevention of oxidative damage during the glycation process may indicate other mechanisms for the inhibition of generations of AGEs [32]. The evaluation of the effects of the extracts on free thiol groups as an index of protein oxidation in the glycated albumin samples revealed that MCE and BPE significantly suppressed and limit the oxidation of thiol group of albumin. Thus $C$. alata could counteract oxidative modifications that could be induced by glycation.

The antiglycation potential of the extracts was also substantiated through the inhibition of $\beta$-amyloid fibril formation in glycated albumin. Glycation increases the level of amyloid cross $\beta$-structure, thus aggravating the cytotoxicities of protein aggregation and in general hyperglycaemia [33]. These results plainly demonstrated that MCE and

Table 3 Drug-like natures of emodin, quercetin, chrysoeriol, kaempferol, and acarbose

\begin{tabular}{llllll}
\hline Properties & Emodin & Quercetin & Chrysoeriol & Kaempferol & Acarbose \\
\hline Molecular weight $(\mathrm{g} / \mathrm{mol})$ & 270.24 & 302.24 & 300.26 & 286.24 & 645.60 \\
Log $P$ & 1.87 & 1.23 & 2.18 & 1.58 & -6.22 \\
Lipinski & Yes & Yes & Yes & Yes & No \\
Ghose & Yes & Yes & Yes & Yes & No \\
\hline
\end{tabular}


Table 4 Antiglycation properties of the aqueous extracts of dried leaves of C. alata

\begin{tabular}{llll}
\hline Extracts & Inhibition of albumin glycation (\%) & Inhibition of oxidation of thiol groups (nmol/mg protein) & Inhibition of $\beta$-amyloid aggregation (\%) \\
\hline BPE & $71.33 \pm 2.45^{\mathrm{a}}$ & $2.32 \pm 0.01^{\mathrm{a}}$ & $109.67 \pm 1.45^{\mathrm{a}}$ \\
ARE & $54.22 \pm 1.58^{\mathrm{b}}$ & $1.95 \pm 0.02^{\mathrm{b}}$ & $228.67 \pm 7.51^{\mathrm{b}}$ \\
MCE & $81.65 \pm 3.60^{\mathrm{a}}$ & $3.17 \pm 0.06^{\mathrm{c}}$ & $73.43 \pm 0.57^{\mathrm{c}}$ \\
\hline
\end{tabular}

Different letters within the column designate significant differences $(p<0.05)$

$B P E$ butanol partitioned extract, $A R E$ aqueous residual extract, $M C E$ methanol crude extract

BPE significantly decreased the level of amyloid $\beta$-structure of albumin compared to ARE. There is an association between the carbohydrate-digesting enzyme inhibitory potentials and the ability of the extracts to inhibit the formation of AGEs. Thus, the antiglycaemic and antiglycation properties of the plant could interrelate. Although the biological functionality of $C$. alata has been claimed in the traditional system of medicine and had been shown by experimental studies [34, 35], the investigated biological properties could be responsible for the acclaimed medicinal values of this botanical. The study suggests the methanol extracts of $C$. alata could inhibit amyloid fibril formation thereby decreasing the tendency of hyperglycaemia to induce fibrillar aggregation. This shows that the plant could protect against cross- $\beta$-structure formation of albumin from $\alpha$-helix possibly by concealing the glycation sites. The extracts could be considered to have a significant inhibitory activity that might contribute to their claimed medicinal activities. The phenolics and flavonoids contents of plant extracts correlate with the antiglycation properties; thus, these phytochemicals could be assumed to protect against the development of AGEs [36]. BPE has shown more biological activity than ARE in general. This observation was in agreement with the previous report that n-butanol fractions of an extract of C. alata had the antidiabetic property [20]. The study also showed that the butanol fraction of the methanolic extract of the leaves of $C$. alata could comprise inhibitors of hydrolases thus aiding a possibility of developing alternative therapy against secondary complications that could be associated with diabetic conditions.

\section{Conclusion}

The dried leaf of the methanolic extract of $C$. alata contains good anti-hyperglycaemic and preventive agents for albumin glycation. Compared to the aqueous residual extract, the antiglycaemic and antiglycation potential were more significant in the butanol fraction. Studies through the in silico docking showed that amylase, glucosidase, and sucrase inhibition by the verified phytochemicals expected to be found in the plant occurred with the highest bonding efficiency and hydrophobic interaction. The in silico study revealed that phytochemical components of $C$. alata have a high affinity to the selected hydrolases; thus, the plant could be suggested as one of the possible sources of therapeutic agents to reduce the activities of the enzymes and hyperglycaemia.

\section{Abbreviations}

AGE: Advanced glycation end product; ARE: Aqueous residual extract; BPE: Butanol partitioned extract; MCE: Methanol crude extract

\section{Acknowledgements}

The authors are grateful to the members of the Department of Biochemistry, McPherson University, Seriki Sotayo, Nigeria, for their assistance. BJO appreciates Mr. B. D. Olowookere of the Biochemistry Laboratory, Kings University, Odeomu, Nigeria, for his assistance in the authentication of the plant material.

\section{Authors' contributions}

BJO and IFO conceived, designed, and performed the experiments. The manuscript was written, proof-read, and approved by the authors.

\section{Funding}

Not applicable

Availability of data and materials

All data generated or analysed during this study are included in this published article.

\section{Ethics approval and consent to participate}

Not applicable

\section{Consent for publication}

Not applicable

\section{Competing interests}

The authors declare that they have no competing interests.

Received: 16 November 2019 Accepted: 28 July 2020

Published online: 20 October 2020

\section{References}

1. Orasanu G, Plutzky J (2009) The pathologic continuum of diabetic vascular disease. J Am Coll Cardiol 53(5 Suppl):S35-S42

2. Chawla A, Chawla R, Jaggi S (2016) Microvasular and macrovascular complications in diabetes mellitus: distinct or continuum? Indian J Endocrinol Metab 20(4):546-551

3. Meloni G, Meloni T (1996) Glyburide-induced acute haemolysis in a G6PDdeficient patient with NIDDM. Br J Haematol 92(1):159-160

4. Gale EA (2001) Lessons from triglitazones: a story of drug development. Lancet 357:1870-1875

5. Monami M, Luzzi C, Lamanna C, Chiasserini V, Addante F, Desideri CM, Masotti G, Marchionni N, Mannucci E (2006) Three-year mortality in diabetic patients treated with different combinations of insulin secretagogues and metformin. Diabetes Metab Res Rev 22(6):477-482

6. Dahlqvist A (1964) Method for assay of intestinal disaccharides. Anal Biochem 7:18-25

7. Bernfeld P (1955) Amylase, $a$ and $\beta$. In: Colowick SP, Kaplan NO (eds) Methods in enzymology. Academic Press, New York, NY, USA, pp 149-158

8. Kim YM, Jeong YK, Wang MH, Lee YH, Rhee HI (2005) Inhibitory effect of pine extract on alpha-glucosidase activity and postprandial hyperglycaemia. Nutrition 21:756-761

9. Honda M, Hara Y (1993) Inhibition of rat small intestinal sucrase and aglucosidase activities by tea polyphenols. Biosci Biotechnol Biochem 57: 123-124

10. Safari M, Sheikh N, Kashani KM (2010) Study on the effect of vitamin C on the in vitro albumin glycation reaction. Iran J Pharm Res 2010:275-279 
11. Furth AJ (1988) Methods for assaying nonenzymatic glycosylation. Anal Biochem 175:347-360

12. Ellman GL (1959) Tissue sulfhydryl groups. Arch Biochem Biophys 82:70-77

13. Klunk WE, Jacob RF, Mason RP (1999) Quantifying amyloid by Congo red spectral shift assay. Methods Enzymol 309:285-305

14. Liu A, Xu L, Zou Z, Yang S (2009) Studies on chemical constituents from leaves of Cassia alata. Zhongguo Zhong Yao Za Zhi 34(7):861-863

15. Fernand VE, Dinh DT, Washington SJ, Fakayode SO, Losso JN, van Ravenswaay RO, Warner IM (2008) Determination of pharmacologically active compounds in root extracts of Cassia alata L. by use of high performance liquid chromatography. Talanta. 74(4):896-902 https://doi.org/ 10.1016/.t.talanta.2007.07.033

16. Daina A, Michielin O, Zoete V (2017) SwissADME: a free web tool to evaluate pharmacokinetics, drug-likeness and medicinal chemistry friendliness of small molecules. Sci Rep 7:42717 https://doi.org/10.1038/ srep42717

17. Oso BJ, Olowookere BD (2018) A study on the total phenolics and antioxidant properties of different solvent extracts of dried leaves of Cassia alata (L.) Roxb. Medicinal Plants 10(4):348-352

18. Oso BJ, Karigidi KO (2019) Inhibitory action of dried leaf of Cassia alata (Linn.) Roxb against lipoxygenase activity and nitric oxide generation. Scientia Agropec 10(2):185-190

19. Subramanian DP (2001) Venugopal S. Phytochemical investigation of Cassia alata Linn. flowers through various in vitro antioxidant assays. Int J Pharm Tech 3(4):3521-3534

20. Varghese GK, Bose LV, Habtemariam S (2013) Antidiabetic components of Cassia alata leaves: identification through a-glucosidase inhibition studies. Pharm Biol 51(3):345-349 https://doi.org/10.3109/13880209.2012.729066

21. Proença C, Freitas M, Ribeiro D, Oliveira EFT, Sousa JLC, Tomé SM, Ramos MJ, Silva AMS, Fernandes PA, Fernandes E (2017) a-Glucosidase inhibition by flavonoids: an in vitro and in silico structure-activity relationship study. J Enzyme Inhib Med Chem 32(1):1216-1228 https://doi.org/10.1080/14756366. 2017.1368503

22. Hara Y, Honda M (1990) The inhibition of alpha amylase by tea polyphenols. Agric Biol Chem 54:1939-1945

23. Nain P, Saini V, Sharma S, Nain J (2012) Antidiabetic and antioxidant potential of Emblica officinalis Gaertn. leaves extract in streptozotocininduced type-2 diabetes mellitus (T2DM) rats. J Ethnopharmacol 142(1):65-71

24. Ben Younes A, Ben Salem M, El Abed H, Jarraya R (2018) Phytochemical screening and antidiabetic, antihyperlipidemic, and antioxidant properties of Anthyllis henoniana (Coss.) flowers extracts in an alloxan-induced rats model of diabetes. Evid-Based Complem Alt Med 2018:1-14 https://doi.org/10. $1155 / 2018 / 8516302$

25. Cosconati S, Forli S, Perryman AL, Harris R, Goodsell DS, Olson AJ (2010) Virtual screening with AutoDock: theory and practice. Expert Opin Drug Discovery 5(6):597-607

26. Rauter AP, Martins A, Borges C, Mota-Filipe H, Pinto R, Sepodes B, Justino J (2010) Antihyperglycaemic and protective effects of flavonoids on streptozotocin-induced diabetic rats. Phytother Res 24:S133-S138 https:// doi.org/10.1002/ptr.3017

27. Lipinski CA, Lombardo F, Dominy BW, Feeney PJ (2001) Experimental and computational approaches to estimate solubility and permeability in drug discovery and development settings. Adv Drug Deliv Rev 46(1-3):3-26 https://doi.org/10.1016/s0169-409x(00)00129-0

28. Ghose AK, Viswanadhan VN, Wendoloski JJ (1999) A knowledge-based approach in designing combinatorial or medicinal chemistry libraries for drug discovery. 1. A qualitative and quantitative characterization of known drug databases. J Comb Chem 1(1):55-68 https://doi.org/10.1021/cc9800071

29. Ma HY, Gao HY, Sun L, Huang J, Xu XM, Wu LJ (2011) Constituents with aglucosidase and advanced glycation end-product formation inhibitory activities from Salvia miltiorrhiza Bge. J Nat Med 65(1):37-42

30. Gkogkolou P, Böhm M (2012) Advanced glycation end products-key players in skin aging. Dermatoendocrin 4(3):259-270

31. Singh VP, Bali A, Singh N, Jaggi AS (2014) Advanced glycation end products and diabetic complications. Kor J Phys Pharm 18(1):1-14

32. Rout S, Banerjee R (2007) Free radical scavenging, anti-glycation and tyrosinase inhibition properties of a polysaccharide fraction isolated from the rind from Punica granatum. Bioresour Technol 98(16):3159-3163

33. Emendato A, Milordini G, Zacco E, Sicorello A, Piaz FD, Remo Guerrini R, Thorogate R, Picone D, Pastore A (2018) Glycation affects fibril formation of
A $\beta$ peptides. J Biol Chem 293(34):13100-13111 https://doi.org/10.1074/jbc. RA118.002275

34. Singh B, Nadkarni JR, Vishwakarm RA, Bharate SB, Nivsarkar M, Anandjiwala S (2012) The hydroalcoholic extract of Cassia alata (Linn.) leaves and its major compound rhein exhibits antiallergic activity via mast cell stabilization and lipoxygenase inhibition. J Ethnopharmacol 141(1):469-473

35. Rekha PD, Vasavi HS, Vipin C, Saptami K, Arun AB (2017) A medicinal herb Cassia alata attenuates quorum sensing in Chromobacterium violaceum and Pseudomonas aeruginosa. Lett Appl Microbiol 64(3):231-238 https://doi.org/ 10.1111/lam. 12710

36. Yeh WJ, Hsia SM, Lee WH, Wu CH (2017) Polyphenols with antiglycation activity and mechanisms of action: a review of recent findings. J Food Drug Anal 25(1):84-92 https://doi.org/10.1016/j.jfda.2016.10.017

\section{Publisher's Note}

Springer Nature remains neutral with regard to jurisdictional claims in published maps and institutional affiliations.

\section{Submit your manuscript to a SpringerOpen ${ }^{\circ}$ journal and benefit from:}

- Convenient online submission

- Rigorous peer review

- Open access: articles freely available online

High visibility within the field

- Retaining the copyright to your article

Submit your next manuscript at $\boldsymbol{\nabla}$ springeropen.com 